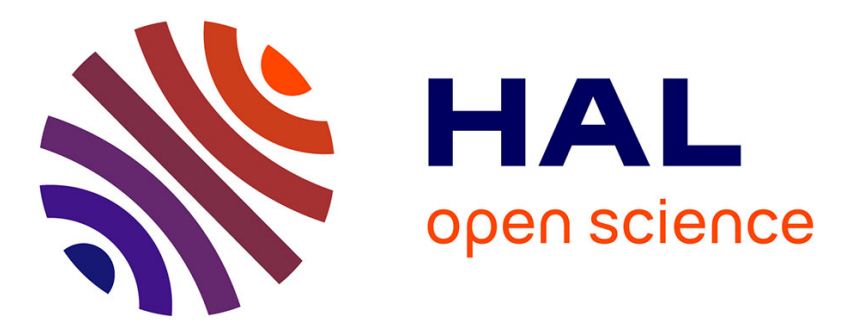

\title{
Cost-effectiveness of a tetravalent human papillomavirus vaccine in Germany
}

\author{
Peter Hillemanns, Karl Ulrich Petry, Nathalie Largeron, Ruth Mcallister, \\ Keith Tolley, Katharina Büsch
}

\section{- To cite this version:}

Peter Hillemanns, Karl Ulrich Petry, Nathalie Largeron, Ruth Mcallister, Keith Tolley, et al.. Costeffectiveness of a tetravalent human papillomavirus vaccine in Germany. Journal of Public Health, 2008, 17 (2), pp.77-86. 10.1007/s10389-008-0228-3 . hal-00478187

\section{HAL Id: hal-00478187 \\ https://hal.science/hal-00478187}

Submitted on 30 Apr 2010

HAL is a multi-disciplinary open access archive for the deposit and dissemination of scientific research documents, whether they are published or not. The documents may come from teaching and research institutions in France or abroad, or from public or private research centers.
L'archive ouverte pluridisciplinaire HAL, est destinée au dépôt et à la diffusion de documents scientifiques de niveau recherche, publiés ou non, émanant des établissements d'enseignement et de recherche français ou étrangers, des laboratoires publics ou privés. 


\title{
Cost-effectiveness of a tetravalent human papillomavirus vaccine in Germany
}

\author{
Peter Hillemanns $\cdot$ Karl Ulrich Petry • \\ Nathalie Largeron • Ruth McAllister • Keith Tolley • \\ Katharina Büsch
}

Received: 2 June 2008 / Accepted: 19 September 2008 / Published online: 17 October 2008

(C) Springer-Verlag 2008

\begin{abstract}
Aim Clinical trials have demonstrated the efficacy of the tetravalent human papillomavirus (HPV) vaccination in the prevention of cervical cancer and genital warts associated with HPV types $6,11,16$ and 18 . We used an empirically calibrated Markov cohort model of the natural history of HPV to assess the cost-effectiveness of the vaccine administered to 12-year-old girls alongside existing cervical screening programmes in Germany.

Subjects and methods The model estimated cervical cancer (CC), cervical intraepithelial neoplasia (CIN) and genital wart lifetime risks and total lifetime health care costs, life years gained and quality-adjusted life years (QALY) gained. The analysis was conducted from the perspective of the German health care payer.

Results In the base case (considering a lifetime duration of protection and $100 \%$ efficacy) it was estimated that 2,835
\end{abstract}

\section{P. Hillemanns $(\bowtie)$}

Medizinische Hochschule Hannover,

Carl-Neubergstr. 1,

30625 Hannover, Germany

e-mail: hillemanns.peter@mh-hannover.de

\section{K. U. Petry}

Frauenklinik im Klinikum der Stadt Wolfsburg,

Wolfsburg, Germany

N. Largeron

Sanofi Pasteur MSD,

Lyon, France

R. McAllister $\cdot$ K. Tolley

Mapi Values,

Bollington, UK

K. Büsch

Sanofi Pasteur MSD,

Leimen, Germany cervical cancer cases and 679 deaths could be prevented among a cohort of 400,000 , at an incremental cost per QALY gained of $10,530 €$. A total of 120 girls needed to be vaccinated to prevent 1 case of CC. Cost-effectiveness is sensitive to a duration of protection of less than 20 years and to the discount rate for costs and benefits.

Conclusion A policy of vaccinating adolescent girls has been recommended by the German Standing Committee on Vaccinations. This study has demonstrated that such a policy is cost-effective based on thresholds of costeffectiveness that apply in Germany.

Keywords Human papillomavirus (HPV) vaccine . Cost-effectiveness · Germany

\section{Introduction}

Cervical cancer is among the most common female cancers in many countries. In Germany, there are an estimated 6,190 new cases every year and about 1,660 deaths (Robert Koch-Institut 2008). Epidemiological research conducted during the last 15-20 years has provided overwhelming evidence for the aetiological role for infection with certain types of human papillomavirus (HPV) as the primary cause of cervical cancer. This virus is also responsible of other anogenital cancers (vulva, vaginal, anus, penile), head and neck cancers and genital warts (Munoz et al. 2006).

In Germany, cervical cancer is one of the target cancers covered by the statutory early detection cancer screening programme which was introduced in West Germany in 1971 and expanded to the eastern part of the country in 1991 (Schenck and von Karsa 2000). Women covered by statutory health insurance (over $90 \%$ of the population) are eligible to receive an annual cervical examination including 
a Papanicolaou (Pap) smear beginning at the age of 20 years (Schenck and von Karsa 2000). Since the programme is based on opportunistic screening, the attendance rates have been low and only reached about $50 \%$ of females by the end of the 1990s (Schenck and von Karsa 2000). Therefore, screening alone cannot be expected to prevent all cases of cervical cancer.

The development of a prophylactic vaccine against HPV is a major breakthrough in the prevention of invasive cervical cancer. In 2006, the first prophylactic tetravalent HPV recombinant vaccine (HPV types 6,11,16,18) was granted marketing authorisation in the European Union. This tetravalent vaccine is indicated for the prevention of high-grade cervical dysplasia (CIN 2/3), cervical carcinoma, high-grade vulvar dysplastic lesions (VIN 2/3) and external genital warts causally related to HPV types 6,11 , 16 and 18. In 2007, a bivalent vaccine (HPV types 16 and 18), indicated for the prevention of CIN grades 2 and 3 and cervical cancer causally related to HPV types 16 and 18, was approved for use by the European Medicines Agency. Both vaccines have been shown to be highly effective in large phase III clinical trials (FUTURE II Study Group 2007; Paavonen et al. 2007).

The objective of this study was to conduct a costeffectiveness analysis of a tetravalent HPV recombinant vaccine in 12-year-old girls alongside the existing cervical cancer screening programme in Germany.

\section{Study methodology}

\section{Model structure}

A published and validated US Markov model of the natural history of HPV infection and cervical cancer (Myers et al. 2000) has recently been adapted to the UK (Kulasingam et al. 2008). We adapted this model to a German health care context to provide the basis of the cost-effectiveness analysis.

The Markov model follows a cohort of girls aged 12 up to age 85 through different health states covering HPV infection, cervical intraepithelial neoplasia (CIN), cervical cancer and genital warts. Movement between the health states is based on annual transition probabilities. Each year, an age-specific risk of acquiring an oncogenic HPV infection is applied to women in the cohort. Then, women infected with HPV can, with varying levels of probability, return to a 'well' state, suffer a persistent infection, progress to CIN 1, or in some cases, progress directly to CIN 2 . Women who develop CIN 1, CIN 2 or CIN 3 are at risk of developing cervical cancer. The severity of cervical cancer is staged according to the Fédération Internationale de Gynécologie et d'Obstétrique (FIGO) classification system
(FIGO I-IV). Each year women face an age-specific risk of dying from other causes.

Each year there is a risk of developing genital warts which varies depending on the woman's age. It is assumed that the genital warts will be cured within the year and the woman will return to a normal health state. Hence, the occurrence of genital warts is not associated with a disease state, but is rather considered as a transitory event in the model.

To be representative of the German health care context, the Markov model was adapted in three main ways. Firstly, the model was structurally adapted to reflect the screening and treatment pathways in Germany. In the USA and the majority of European countries, cytology screening results, using Pap smears, are classified according to the Bethesda system which reports LSIL (low-grade squamous intraepithelial lesion also known as CIN 1) and HSIL (high-grade squamous intraepithelial lesion also known as CIN 2/3). In Germany, the PAP (Munich II) system is employed (Schenck and Soost 1995). Therefore, the parameters in the model were adapted to correspond with the PAP system.

Secondly, the model was populated with German epidemiological and economic data derived from various sources that are detailed below. Thirdly, the model was calibrated to fit the age-specific cancer incidence curve for a screened population (Krebsregister 2003) and the results from a published decision-analytic model on the natural history of cervical cancer developed specifically for Germany (Siebert et al. 2006).

The model was programmed using the software TreeAge Pro (TreeAge Software Inc., Williamstown, MA, USA).

\section{Vaccination strategy}

We compared a routine vaccination programme of 12-yearold girls with a tetravalent HPV vaccine to the current cervical cancer screening programme. In the base case analysis it was assumed that vaccination coverage would be $80 \%$ of the eligible population and that screening practices would be unaffected by vaccination status.

\section{Natural history parameters}

Natural history parameters for progression and regression of disease used in the UK model were assumed to apply across Europe; hence, transition probabilities data were first extracted from the UK model (Kulasingam et al. 2008) (Table 1). Then, age-specific rates of HPV infection applied to the model were slightly modified to fit the age-specific cervical cancer incidence curve as part of the calibration process (Krebsregister 2003). The rates were higher for the age 20 and 21, which is consistent with the fact that 
Table 1 Natural history parameters used in the model

\begin{tabular}{|c|c|c|c|c|}
\hline Parameter & Age & $\begin{array}{l}\text { Transition } \\
\text { probability }\end{array}$ & $\begin{array}{l}\text { Time } \\
\text { period }\end{array}$ & Source \\
\hline \multicolumn{5}{|l|}{ Normal } \\
\hline \multirow[t]{4}{*}{ Normal to HPV-infected state } & $14-18$ & $0.020-0.080$ & \multirow[t]{4}{*}{12 months } & \multirow[t]{4}{*}{ Calibrated from Canfell et al. (2004) } \\
\hline & $19-29$ & $0.160-0.250$ & & \\
\hline & $30-39$ & $0.025-0.045$ & & \\
\hline & $50+$ & 0.0095 & & \\
\hline \multicolumn{5}{|l|}{ HPV infection } \\
\hline HPV infection to CIN 1 or CIN 2 & All & 0.0959 & 12 months & \multirow[t]{2}{*}{ Canfell et al. (2004) } \\
\hline Proportion of HSIL that are CIN 2 & All & 0.1350 & - & \\
\hline \multicolumn{5}{|l|}{$\mathrm{CIN}$} \\
\hline \multirow[t]{4}{*}{ CIN 1 to well } & $12-24$ & 0.7000 & \multirow[t]{4}{*}{18 months } & \multirow{4}{*}{$\begin{array}{l}\text { Calibrated from Canfell et al. (2004) } \\
\text { and Myers et al. (2000) }\end{array}$} \\
\hline & $25-39$ & 0.5000 & & \\
\hline & $40-49$ & 0.2700 & & \\
\hline & $50+$ & 0.1000 & & \\
\hline \multirow[t]{2}{*}{ CIN 1 to $\mathrm{CIN} 2$} & $16-34$ & 0.0297 & \multirow[t]{2}{*}{12 months } & \multirow[t]{17}{*}{ Canfell et al. (2004) } \\
\hline & $35+$ & 0.1485 & & \\
\hline CIN 1 to CIN 3 & All & 0.0301 & 12 months & \\
\hline \multirow[t]{2}{*}{ CIN 1 to HPV-infected state } & $16-34$ & 0.2248 & \multirow[t]{2}{*}{12 months } & \\
\hline & $35+$ & 0.1124 & & \\
\hline $\begin{array}{l}\text { Proportion CIN } 1 \text { regressing } \\
\text { directly to well }\end{array}$ & All & 0.90 & - & \\
\hline \multirow[t]{3}{*}{ CIN 2 to $\mathrm{CIN} 3$} & $16-34$ & 0.0389 & \multirow[t]{3}{*}{12 months } & \\
\hline & $35-44$ & 0.0797 & & \\
\hline & $45+$ & 0.1062 & & \\
\hline CIN 2 to $\mathrm{CIN} 1$ & All & 0.2430 & 12 months & \\
\hline CIN 2 to well or HPV-infected state & All & 0.1901 & 12 months & \\
\hline $\begin{array}{l}\text { Proportion CIN } 2 \text { regressing } \\
\text { directly to well }\end{array}$ & All & 0.90 & - & \\
\hline CIN 3 to $\mathrm{CIN} 1$ & All & 0.0000 & 12 months & \\
\hline CIN 3 to $\mathrm{CIN} 2$ & All & 0.0135 & 12 months & \\
\hline \multirow[t]{2}{*}{ CIN 3 to well or HPV-infected state } & $16-44$ & 0.0135 & \multirow[t]{2}{*}{12 months } & \\
\hline & $45+$ & 0.0100 & & \\
\hline $\begin{array}{l}\text { Proportion CIN } 3 \text { regressing } \\
\text { directly to well }\end{array}$ & All & 0.50 & - & \\
\hline CIN 3 to invasive cervical cancer & All & 0.013 & 12 months & Canfell et al. (2004) \\
\hline \multicolumn{5}{|l|}{ Cervical cancer } \\
\hline \multicolumn{5}{|l|}{ Progression rates } \\
\hline FIGO stage I & & 0.90 & 48 months & \multirow[t]{4}{*}{ Myers et al. (2000) } \\
\hline FIGO stage II & & 0.90 & 36 months & \\
\hline FIGO stage III & & 0.90 & 15 months & \\
\hline FIGO stage IV & & 0.90 & 12 months & \\
\hline \multicolumn{5}{|l|}{ Probability of symptoms } \\
\hline FIGO stage I & & 0.11 & 12 months & \multirow{4}{*}{$\begin{array}{l}\text { Calibrated from Canfell et al. (2004) } \\
\text { and Myers et al. (2000) }\end{array}$} \\
\hline FIGO stage II & & 0.23 & & \\
\hline FIGO stage III & & 0.60 & & \\
\hline FIGO stage IV & & 0.80 & & \\
\hline
\end{tabular}

acquisition of HPV occurs very quickly after the onset of sexual activity. In addition, using the same approach as others (Siebert et al. 2006), we varied probability of symptoms for FIGO stages to obtain a distribution of cervical cancer stages similar to that of an unscreened population.
Five-year survival by cancer stage inputs were derived from Siebert et al. (2004). Age-specific hysterectomy proportions in the German general population (Siebert et al. 2004) and age-specific incidence of genital warts in women were additional inputs in the model (Hillemanns et al. 2008). The mortality rate of women in the general population comes 
from official statistics (Federal Statistical Office Germany Statistics 2004).

\section{German screening programme}

In Germany, cervical screening is recommended from age 20 (Schenck and von Karsa 2000), with a follow-up of a repeat screen each year if the Pap result is normal (Siebert et al. 2006; Anttila and Jordan 2004; Bollmann et al. 2005). The model was structurally adapted to reflect the current screening pathways in Germany in the case of abnormal results, although substantial differences exist among general physicians in terms of management (Sheriff et al. 2007).

In the model, women presenting with LSIL (PAP III D) were assumed to undergo a repeat Pap smear every 3 months for 1 year, with colposcopy and biopsy if the lesion remains persistent, while those with HSIL (PAP IV) were assumed to undergo repeat cytology, colposcopy and biopsy with immediate effect (Siebert et al. 2006; Bollmann et al. 2005). Women who present with an atypical squamous cell of undetermined significance (ASC-US) result undergo a repeat Pap smear within 6 months, with colposcopy and biopsy if the lesion remains persistent (Siebert et al. 2006; Anttila and Jordan 2004; Bollmann et al. 2005).

The screening coverage rate was age specific, ranging from $17.7 \%$ for the age group $65-69$ years up to $52.6 \%$ for the age group 45-54 years (European Commission 2002). Characteristics of the screening tests are presented in Table 2. Treatment of CIN was assumed to be $100 \%$ effective, resulting in the patient returning to a HPVinfected state without CIN; $90 \%$ of women with CIN 1 and all women with CIN 2/3 were assumed to be treated.

\section{Vaccine efficacy}

Based on recently published randomised clinical trials (Garland et al. 2007; Lacey 2008; FUTURE II Study Group 2007), the vaccine was assumed to be $100 \%$ effective against HPV types 6,11, 16 and 18. In the model, it was estimated that these four types are responsible for $35 \%$ of CIN 1 cases. In addition, $55 \%$ of CIN $2 / 3$ cases and $70 \%$ of cancer cases are caused by HPV types 16 and 18 , and $90 \%$ of cases of genital warts are caused by HPV types 6 and 11 (Clifford et al. 2003, 2005; von Krogh 2001).
A high sustained efficacy against HPV 16/18-related CIN 2/3 has been demonstrated for the tetravalent vaccine in large phase II/III trials with follow-up periods (after start of vaccination) up to 5 years in phase II and up to 4 years in phase III (Lacey 2008). Moreover, a three-dose regimen of the tetravalent HPV vaccine induced high efficacy and stable anti-HPV levels for at least 5 years in a recent study, suggesting that the efficacy of this vaccine will be long lasting (Olsson et al. 2007). Therefore, the base case assumption was that duration of protection would be lifelong without the need for a booster, similar to the approach adopted in other cost-effectiveness analyses (Brisson et al. 2007b; Bergeron et al. 2008; Dasbach et al. 2008; Chesson et al. 2008).

Cross-protection effect of the vaccine was not considered in our analysis, although recent clinical cross-protection efficacy has been demonstrated against ten additional oncogenic human papillomavirus types (Brown 2007).

\section{Costs}

Unit costs are presented in Table 3. The analysis has been carried out from the German health care payer perspective. Medical resource use associated with screening and subsequent disease management, 5 -year costs for treating cervical cancer by FIGO stage as well as costs for treatment of genital warts were derived from three German studies (Petry et al. 2008; Siebert et al. 2004; Hillemanns et al. 2008).

The cost of one $0.5-\mathrm{ml}$ dose of a tetravalent HPV vaccine used in the model is $143.8 €$ and as three doses are required for effective disease prophylaxis the total cost per person vaccinated is $439.8 €$. The unit cost of administration by a general practitioner (GP) is estimated to be $6.5 €$ per vaccination representing the mean fee for a GP visit for single vaccination administration across German federal states and insurance providers.

\section{Utilities and discount rates}

Utility estimates, used to calculate quality-adjusted life years (QALYs), are presented in Table 4. In the absence of European-specific data, these estimates were derived from a US time trade-off study conducted in 150 healthy female

Table 2 Sensitivity and specificity of Pap test, colposcopy and biopsy

\begin{tabular}{lll}
\hline & Value & Source \\
\hline Sensitivity of a Pap test for detecting CIN 1/2 & 0.435 & Petry et al. (2003) \\
Sensitivity of a Pap test for detecting CIN 3/cervical cancer & 0.64 & Karnon et al. (2004) \\
Specificity of a Pap test & 0.95 & Siebert et al. (2006) \\
Sensitivity of colposcopy with biopsy & 0.9 & Canfell et al. (2004) and Mitchell et al. (1998) \\
Specificity of colposcopy with biopsy & 1 & Karnon et al. (2004) \\
\hline
\end{tabular}


Table 3 Costs of detecting and treating precancerous lesions and cervical cancer

\begin{tabular}{lll}
\hline Parameter & Cost $(€)$ & Source \\
\hline Pap smear & 24.8 & a \\
Colposcopy & 23.6 & \\
Biopsy & 106 & \\
Treatment of CIN 1/CIN 2 & 336 & Based on Petry et al. (2008) \\
Treatment of CIN 3 & 1,498 & \\
Treatment of FIGO I & 7,523 & Siebert et al. (2004) \\
Treatment of FIGO II & 12,983 & \\
Treatment of FIGO III & 18,315 & \\
Treatment of FIGO IV & 17,152 & \\
Treatment of genital wart & 550 & Hillemanns et al. (2008) \\
\hline
\end{tabular}

${ }^{\text {a }}$ Outpatient costs come from Kassenärztliche Bundesvereinigung: Einheitlicher Bewertungsmaßstab für ärztliche Leistungen. http:// www.kbv.de/ebm2000plus/EBMGesamt.htm. Accessed 22 Nov 2006

${ }^{\mathrm{b}}$ This represents the mean cost of interventional procedures in Petry et al. (2008), assuming that PAP III and PAP III B were CIN 1 or CIN 2 and that PAP IV were CIN 3

volunteers (Myers et al. 2004). The expected time considered in each state of health was the same as that in a UK analysis using the same core model (Kulasingam et al. 2008). The utility for those surviving cervical cancer was assumed to be 1.0 .

In the absence of specific recommended discount rates for prevention technologies, the base case rates applied were those recommended in Dutch pharmacoeconomic guidelines (Dutch Health Care Insurance Board 2005). Discount rates of $4 \%$ for costs and $1.5 \%$ per annum for future health benefits (LYGs and QALYs) were applied in the base case. Given the high uncertainty in the appropriate discount rate a range from 0 to $5 \%$ for costs and benefits was also applied in sensitivity analysis.

Outputs and analyses

The model was used to produce estimates of cervical cancer, CIN and genital wart lifetime risks, total lifetime costs and incremental cost-effectiveness ratios (ICERs): the incremental cost per life year gained (LYG), and incremental cost per QALY gained.

The number needed to vaccinate (NNV) to prevent cases of cervical cancer is a useful measure of vaccine effectiveness (Brisson et al. 2007a). Using the natural history model, the NNV with the tetravalent HPV vaccine in Germany was estimated. NNV was defined as the number of 12-year-old girls that are needed to be vaccinated to prevent an HPVrelated event during their lifetime, calculated as follows: $\mathrm{NNV}=1 / \mathrm{ARR}$, with ARR representing attributable risk reduction (Brisson et al. 2007a).

One-way sensitivity analysis was undertaken to explore the impact on cost-effectiveness of varying a range of key parameters for duration of vaccine protection, vaccine and administration costs, Pap sensitivity, utilities, discount rates and screening coverage. The impact on cost-effectiveness of a scenario of administering a booster vaccine (one dose) to $50 \%$ of females originally vaccinated was also explored.

\section{Results}

\section{Model validation}

The model was calibrated to predict a lifetime risk of cervical cancer of $3.1 \%$ and a lifetime risk of death due to cervical cancer of $1.08 \%$ in Germany in the absence of screening. Moreover the model predicts the following distribution for FIGO stage at diagnosis (before screening implementation): FIGO I: $38.4 \%$, FIGO II: 30.3\%, FIGO III-IV: $31.3 \%$. These predictions are consistent with findings from Siebert et al. (2006).

As shown in Fig. 1, the model was also calibrated so that the predicted age-specific annual incidence of invasive cervical cancer in the German screened population was similar to the observed data for Germany (Krebsregister 2003), demonstrating the validity of the model adaptations for the German context.

Table 4 Utility values used in the model

\begin{tabular}{lll}
\hline Health status & Utility value & Time period \\
\hline Routine screening Pap smear & 0.98 & 1 month \\
ASC-US diagnosis from Pap smear & 0.94 & 2 months \\
LSIL/HSIL diagnosis from Pap smear & 0.91 & 2 months \\
Genital warts & 0.91 & 85 days \\
CIN 1 & 0.91 & 2 months with 10 months follow-up \\
CIN 2/3 & 0.87 & 2 months \\
FIGO I & 0.76 & 5 years \\
FIGO II-IV & 0.67 & 5 years \\
\hline
\end{tabular}

Source: Myers et al. (2004) and Kulasingam et al. (2008) 
Fig. 1 Simulated and observed cervical cancer incidence for the screened population

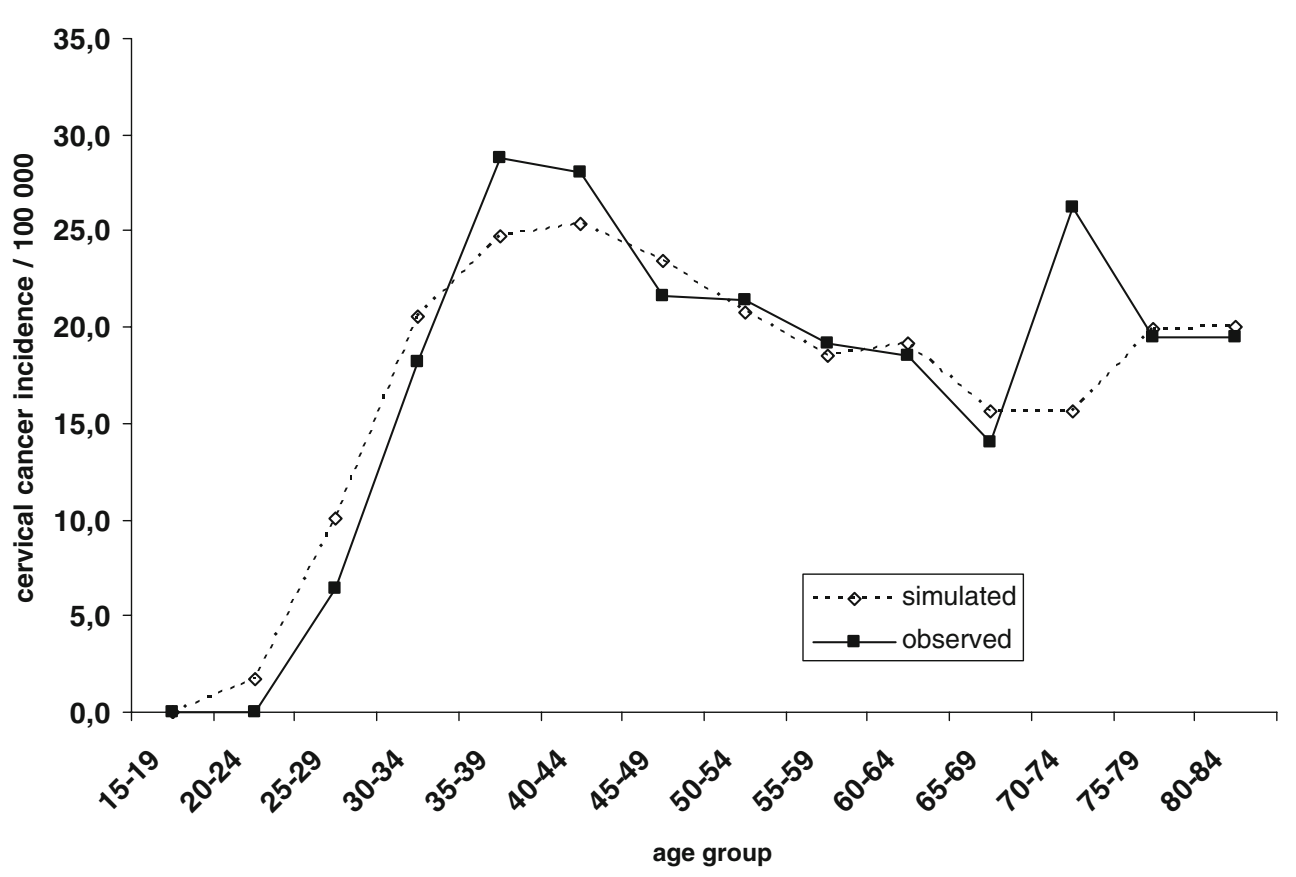

Health benefits

Under base case assumptions (vaccination coverage rate of $80 \%$ and lifelong duration of protection) for a birth cohort of about 400,000 females in Germany, the model estimates that 2,835 cervical cancer cases and 679 deaths could be avoided. In addition, 7,776, 5,921 and 9,962 cases of detected CIN 1, 2 and 3 cases, respectively, and 28,310 cases of genital warts could be avoided (Table 5).

\section{Base case cost-effectiveness analysis}

The incremental cost-effectiveness of a screening plus vaccination programme from a health care payer perspective in Germany versus screening alone was estimated to be 15,684 € per LYG and 10,530 € per QALY gained (Table 6). These ratios are well below the incremental cost-effectiveness threshold relevant to Germany of 50,000 € per QALY. Therefore, a vaccination programme with a tetravalent HPV vaccine alongside the current screening programme can be considered as a cost-effective strategy.
The cost per cervical cancer avoided (undiscounted) is estimated at 24,519 $€$ and the cost per event avoided (cervical cancer, $\mathrm{CIN}$ or female genital warts) at $1,253 €$.

\section{Sensitivity analyses}

The base case assumes lifetime duration of protection for vaccination. Incremental cost-effectiveness was sensitive to durations of protection of less than 20 years, but not for longer durations up to lifetime. Furthermore, a scenario in which booster vaccination is provided (after 10 years) for $50 \%$ of females originally vaccinated in order to ensure lifetime protection produced an increased cost-effectiveness ratio compared to the base case, primarily due to the impact of the increased cost of providing a booster (Table 7).

Cost-effectiveness was very sensitive to the discount rate used, with higher joint discount rates for costs and benefits resulting in higher cost-effectiveness ratios (Table 7). If costs and health benefits were jointly discounted at 3\%, which is similar to the rate recommended in several economic evaluation guidelines across Europe, the incre-

Table 5 Estimated number of cases avoided per 400,000 cohort $^{\mathrm{a}}$

\begin{tabular}{|c|c|c|c|c|c|c|}
\hline Strategy & $\begin{array}{l}\text { Cervical } \\
\text { cancer }\end{array}$ & $\begin{array}{l}\text { Deaths from } \\
\text { cervical cancer }\end{array}$ & $\begin{array}{l}\text { CIN } 3 \\
\text { detected }\end{array}$ & $\begin{array}{l}\text { CIN } 2 \\
\text { detected }\end{array}$ & $\begin{array}{l}\text { CIN } 1 \\
\text { detected }\end{array}$ & $\begin{array}{l}\text { Genital } \\
\text { warts }\end{array}$ \\
\hline Screening only & 4,783 & 1,146 & 21,514 & 12,868 & 23,455 & 40,299 \\
\hline Screening and vaccination & 1,948 & 468 & 11,552 & 6,947 & 15,679 & 11,989 \\
\hline Cases avoided & 2,835 & 679 & 9,962 & 5,921 & 7,776 & 28,310 \\
\hline
\end{tabular}

${ }^{a}$ Assuming $80 \%$ coverage rate, lifetime duration of protection 
Table 6 Incremental cost-effectiveness from a German health care payer perspective

\begin{tabular}{llllll}
\hline & Costs $(€)$ & Mean LYGs & Incremental cost/LYG $(€)$ & QALYs & Incremental cost/QALY $(€)$ \\
\hline Screening only & 314.1 & 42.55 & - & 42.4989 & - \\
Screening + vaccination & 612.2 & 42.569 & 15,684 & 42.5272 & 10,530 \\
\hline
\end{tabular}

mental cost-effectiveness increased to $18,636 €$ per QALY gained. If the discount rate is $5 \%$ for both costs and benefits, the ICER increased to $42,493 €$ per QALY gained. In contrast, with zero discounting of costs and benefits the ICER was less than 3,049 € per QALY gained.

The cost-effectiveness ratio was insensitive to changes in treatment costs, efficacy, utility parameters and application of a zero disutility for a routine Pap smear test (Table 7). Varying the sensitivity of the Pap smear for detection of CIN $1 / 2$ or CIN 3 had a small impact on the costeffectiveness ratio.

The impact of different screening strategies associated or not with vaccination was also considered. In our base case analysis, 2,835 incremental cases of cervical cancer and 679 incremental deaths could be avoided thanks to the introduction of the HPV vaccination compared to the current screening programme alone. If the screening coverage rate was increased by $20 \%$ without HPV vaccination, only 717 incremental cases of cervical cancer and 231 incremental deaths from cervical cancer could be avoided. If the screening coverage rate decreased by $20 \%$ after the vaccination programme implementation, 2,442 additional cancer cases and 541 additional deaths could be avoided. In this context, introducing HPV vaccination in association with a screening programme (less or as efficient as the current one) appeared to be more efficient than only improving the existing screening intervention.

Number needed to vaccinate

The NNV to prevent one case of cervical cancer was estimated to be 120 based on a birth cohort of 400,000 12year-old girls. For this we assumed a vaccination coverage rate of $100 \%$. For CIN 1, CIN 2 and CIN 3 related to HPV the NNV to prevent one case was estimated by the model to be 45, 55 and 33, respectively, and the NNV for genital wart was estimated to be 11. Six girls need to be vaccinated to prevent one HPV-related clinical event.
Table 7 Sensitivity analysis for key parameters
${ }^{\mathrm{a}}$ One dose of booster given 10 years after the three doses in $50 \%$ of the cohort. No efficacy is assumed after 10 years for the $50 \%$ of non-vaccinated girls

\begin{tabular}{|c|c|c|}
\hline & Incremental cost/LYG $(€)$ & Incremental cost/QALY $(€)$ \\
\hline Base case & 15,684 & 10,530 \\
\hline \multicolumn{3}{|l|}{ Duration of protection } \\
\hline Lifelong achieved with a booster ${ }^{\mathrm{a}}$ & 24,943 & 17,034 \\
\hline 20 years & 28,991 & 19,445 \\
\hline \multicolumn{3}{|l|}{ Vaccine efficacy } \\
\hline $90 \%$ efficacy & 16,872 & 11,681 \\
\hline \multicolumn{3}{|l|}{ Vaccine cost } \\
\hline$-20 \%$ & 12,053 & 8,092 \\
\hline $20 \%$ & 19,321 & 12,972 \\
\hline \multicolumn{3}{|l|}{ Treatment cost (CIN and cancer) } \\
\hline$-20 \%$ & 16,311 & 10,951 \\
\hline $20 \%$ & 15,063 & 10,113 \\
\hline \multicolumn{3}{|l|}{ Pap sensitivity for detection of CIN 1} \\
\hline $50 \%$ & 16,394 & 10,731 \\
\hline \multicolumn{3}{|c|}{ Pap sensitivity for detection of CIN $2 / 3$} \\
\hline $55 \%$ & 11,400 & 8,211 \\
\hline $75 \%$ & 23,069 & 12,972 \\
\hline \multicolumn{3}{|l|}{ Utilities } \\
\hline$-50 \%$ duration & NA & 11,037 \\
\hline$+50 \%$ duration & NA & 9,313 \\
\hline \multicolumn{3}{|l|}{ Discount rate for costs/benefits } \\
\hline $0 \% / 0 \%$ & 4,138 & 3,049 \\
\hline $3 \% / 3 \%$ & 30,258 & 18,636 \\
\hline $5 \% / 5 \%$ & 81,632 & 42,493 \\
\hline $5 \% / 0 \%$ & 7,386 & 5,442 \\
\hline Exclusion of genital warts & 16,689 & 11,658 \\
\hline
\end{tabular}




\section{Discussion}

Although previous studies have assessed the cost-effectiveness of HPV vaccination in other European countries (Bergeron et al. 2008; Dasbach et al. 2008), this is the first analysis conducted on HPV vaccination Germany. Until now, cost-effectiveness studies specific to Germany have focussed on the cost-effectiveness of several screening strategies (Mittendorf et al. 2003; Siebert et al. 2004; Sheriff et al. 2007). Based on a vaccination coverage rate of $80 \%$, the use of a quadrivalent vaccine alongside the current national cervical cancer screening programme was found to be a cost-effective public health initiative compared to screening alone, with an incremental cost per QALY gained and LYG gained that was well within the accepted threshold for cost-effectiveness in Germany (Siebert et al. 2004). In terms of health benefits the model has shown that the introduction of a tetravalent vaccine has the potential to substantially reduce the public health burden associated with cervical cancer, with an estimated reduction of nearly 3,000 cases and 700 deaths for a cohort of 400,000 females vaccinated at the age of 12 . Sensitivity analysis has shown that the results are relatively insensitive to varying the base case parameters for screening and vaccine coverage rates, natural history, Pap smear sensitivity, cost and utility variables. The only variable that results in cost-effectiveness ratios above 50,000 $€$ per QALY gained was if a very short duration of protection is assumed. An incremental cost per LYG above 50,000 € was associated with applying relatively high rates of discounting $(5 \%)$ for both costs and health outcomes. There is much debate regarding the value of the discount rate used, particularly when evaluating public health programmes such as vaccination. Discounting may undervalue preventive interventions for which the benefits appear long after the costs have been paid, such as HPV vaccination programmes (Crott 2007).

We note some limitations in our analysis. Firstly, utility estimates, required to calculate cost per QALY, were derived from a study conducted in the USA (Myers et al. 2004). To our knowledge, no specific data for Germany, or any other European countries, have been published so far. In addition, our utility estimates are conservative compared with estimates used in other published cost-effectiveness analyses (Brisson et al. 2007b; Goldie et al. 2004). Secondly, we considered a compliance of $100 \%$ for the three doses of the vaccines. It may happen that some girls received only two doses instead of three, although it is difficult to make an assumption on this. Lastly, previous German economic studies suggested that HPV testing would improve screening performance (Sheriff et al. 2007). However, we decided not to include HPV testing in our analysis as HPV testing is not standard practice in Germany.
Our analysis can be considered as conservative in several aspects. Firstly, as we used a Markov model it was not possible to include the herd immunity effects of the vaccination programme. For instance, it is not possible to assess the indirect benefits of the vaccine by avoiding HPVrelated diseases in males. To measure these additional benefits, a dynamic transmission model would be necessary. A number of dynamic models exist (Dasbach et al. 2006), among which two have examined the cost-effectiveness of quadrivalent HPV (6/11/16/18) vaccination strategies in Europe (Jit et al. 2008; Dasbach et al. 2008). Secondly, our model did not cover the cross-protection effect of the vaccine and the impact of the tetravalent HPV vaccine on the prevention of other cancers, in particular vaginal and vulval cancers or laryngeal papillomas, related to HPV types 6, 11, 16 and 18. A recent US cost-effectiveness analysis showed that the inclusion of potential additional benefits of preventing anal, vaginal, vulvar and oropharyngeal cancers could decrease the cost per QALY by at least 20\% (Chesson et al. 2008). Furthermore, indirect costs of lost productivity were not included, which would potentially further improve costeffectiveness from a societal perspective.

Economic analyses such as ours can help to provide information for public health policy and reimbursement decisions on an HPV vaccination programme. In the case of HPV vaccines, it can also highlight the difference between a bivalent and a quadrivalent vaccine. The types 6 and 11 included in the quadrivalent vaccine are responsible for $90 \%$ of genital warts and for around $10 \%$ of CIN 1 . In our model, the cost-effectiveness ratio is increased by $10 \%$ when benefits of the vaccine on genital warts are removed. This result is modest as compared to findings from other countries which can be the results of not having an HPV type specific model. A Canadian cost-effectiveness study showed that the cost-effectiveness ratio of vaccinating a cohort of 12-year-old girls with the quadrivalent (HPV 6/ 11/16/18) and with the bivalent (HPV 16/18) vaccine would be of Canadian $\$ 20,512$ and 31,060/QALY gained, respectively (Brisson et al. 2007b). Another study, conducted by the Centers for Disease Control and Prevention (CDC) in the USA estimated that vaccination of 12-year-old girls with the quadrivalent (HPV 6/11/16/18) vaccine had a costeffectiveness ratio at least $30 \%$ lower than with the bivalent (HPV 16/18) vaccine (Chesson et al. 2008).

To date, there has been limited use of economic analyses for such decisions in Germany compared to some other European countries such as the UK. However, this might change with German insurance companies increasing their focus on cost and forthcoming requirements for economic analysis to be performed as part of the reviews of new interventions by the German Health Technology Agency, the Institute for Quality and Efficiency in Health Care, which advises the Federal Ministry of Health. In addition, 
the German Standing Committee on Vaccinations (STIKO) at the Robert Koch Institute has recommended the introduction of universal vaccination against HPV types 16 and 18 for all girls between the age of 12 and 17 in order to reduce the incidence of cervical cancer in the population (Robert Koch Institute 2007). Our analysis focussed on a single cohort, but dynamic transmission models, which allow seeing the impact of catch-up programmes, conclude that an initial catch-up programme for girls aged up to 18 is likely to be cost-effective (Dasbach et al. 2008; Jit et al. 2008). The STIKO statement includes an assessment of the possible impact of an HPV vaccination programme in Germany. For a 1996 birth cohort and assuming a lifetime vaccination effectiveness rate of $92.5 \%$, it was estimated that the NNV to prevent one case of cervical cancer was 98 . These estimates are similar to the NNV of 120 estimated from our model for Germany.

A policy issue that needs addressing in Germany is the concern that the current policy of annual screening of $>20$ year-old females is sub-optimal. A recent German study demonstrated that cost-effectiveness could be improved with screening intervals of 3-5 years, concluding that the German cervical screening programme was in need of reform (Bischoff-Everding et al. 2006). The effectiveness of existing screening strategies could therefore constrain the cost-effectiveness of screening plus vaccination programmes for HPV infection.

A further policy issue is that there is a risk of lower adherence to cervical cancer screening with a universal vaccination programme, which could be addressed via education campaigns to advise young women of the continued importance of attending cervical screening.

In conclusion, our analysis supports a national programme of adding the HPV tetravalent vaccine in adolescent females to the national cervical screening programme in Germany as a cost-effective strategy from a health care and public health perspective, due to the significant impact it can have on reducing the burden of disease associated with HPV-related diseases.

Acknowledgements The decision to submit this manuscript for publication was taken collectively by all of the authors.

Funding This study was conducted with the financial support of Sanofi Pasteur MSD, Lyon, France.

Conflict of interest statement PH and KUP declared that they have received honoraria from Sanofi Pasteur MSD and/or GSK for speaking at several scientific meetings and for acting as scientific consultant. NL is an employee of Sanofi Pasteur MSD, who commercializes Gardasil ${ }^{\circledR}$ in Europe. KB previously worked for Sanofi Pasteur MSD. RMA and KT previously worked for Mapi Values who were contracted by Sanofi Pasteur MSD to conduct the analysis and to write a previous version of this manuscript.

\section{References}

Anttila A, Jordan J (2004) Epidemiological guidelines for quality assurance in cervical cancer screening. In: European guidelines for quality assurance in cervical cancer screening, pp 1-70

Bergeron C, Largeron N, McAllister R, Mathevet P, Remy V (2008) Cost-effectiveness analysis of the introduction of a quadrivalent human papillomavirus vaccine in France. Int J Technol Assess Health Care 24:10-19

Bischoff-Everding CH, Reimers W, Hopfenmüller W, Kühn W (2006) Kosten-Nutzen-Effektivitätsanalysen des zytologischen Zervixkarzinomscreenings mittels Markov-Analysen (abstract). 56. Kongress der Deutschen Gesellschaft für Gynäkologie und Geburtshilfe, 2006

Bollmann R, Bankfalvi A, Griefingholt H, Trosic A, Speich N, Schmitt C, Bollmann M (2005) Validity of combined cytology and human papillomavirus (HPV) genotyping with adjuvant DNA-cytometry in routine cervical screening: results from 31031 women from the Bonn-region in West Germany. Oncol Rep 13:915-922

Brisson M, Van de Velde N, De Wals P, Boily MC (2007a) Estimating the number needed to vaccinate to prevent diseases and death related to human papillomavirus infection. CMAJ 177:464-468

Brisson M, Van de Velde N, De Wals P, Boily MC (2007b) The potential cost-effectiveness of prophylactic human papillomavirus vaccines in Canada. Vaccine 25:5399-5408

Brown D (2007) HPV type 6/11/16/18 vaccine: first analysis of crossprotection against persistent infection, cervical intraepithelial neoplasia (CIN), and adenocarcinoma in situ (AIS) caused by oncogenic HPV types in addition to 16/18 (abstract G-1720b). 47th Interscience Conference on Antimicrobial Agents and Chemotherapy, Chicago, 17-20 September 2007

Canfell K, Barnabas R, Patnick J, Beral V (2004) The predicted effect of changes in cervical screening practice in the UK: results from a modelling study. Br J Cancer 91:530-536

Chesson HW, Ekwueme D, Sasieni P, Markowitz E (2008) Costeffectiveness of human papillomavirus vaccination in the United States. Emerg Infect Dis 14:244-251

Clifford GM, Smith JS, Aguado T, Franceschi S (2003) Comparison of HPV type distribution in high-grade cervical lesions and cervical cancer: a meta-analysis. Br J Cancer 89:101-105

Clifford GM, Rana RK, Franceschi S, Smith JS, Gough G, Pimenta JM (2005) Human papillomavirus genotype distribution in lowgrade cervical lesions: comparison by geographic region and with cervical cancer. Cancer Epidemiol Biomarkers Prev 14:1157-1164

Crott R (2007) Economic analysis of HPV-vaccines: not so simple? Vaccine 25:7717

Dasbach EJ, Elbasha EH, Insinga RP (2006) Mathematical models for predicting the epidemiologic and economic impact of vaccination against human papillomavirus infection and disease. Epidemiol Rev 28:88-100

Dasbach EJ, Insinga RP, Elbasha EH (2008) The epidemiological and economic impact of a quadrivalent human papillomavirus vaccine $(6 / 11 / 16 / 18)$ in the UK. BJOG 115:947-956

Dutch Health Care Insurance Board (2005) Richtlijnen voor farmacoeconomisch onderzoek; evaluatie en actualisatie College voor zorgverzekeringen http://www.cvz.nl/resources/rpt0510_richtlijnen FEO tcm28-17860.pdf. 27 Oct 2005

European Commission (2002) Percentage of women reporting specific preventive examinations. Eurobarometer 43.0 and 59.0

Federal Statistical Office Germany Statistics (2004) Population: births and deaths. http://www.destatis.de/presse/deutsch/cal 2004. htm\#Explanatory\%20note.website. 29 Dec 2004

Garland SM, Hernandez-Avila M, Wheeler CM, Perez G, Harper DM, Leodolter S et al (2007) Quadrivalent vaccine against human 
papillomavirus to prevent anogenital diseases. N Engl J Med 356:1928-1943

Goldie SJ, Kohli M, Grima D, Weinstein MC, Wright TC, Bosch FX, Franco E (2004) Projected clinical benefits and cost-effectiveness of a human papillomavirus 16/18 vaccine. J Natl Cancer Inst 96:604-615

Hillemanns P, Breugelmans G, Gieseking F, Bénard S, Lamure E, Littlewood KJ, Petry KU (2008) Estimation of the incidence of genital warts and the cost of illness in Germany: a cross-sectional study. BMC Infect Dis 8:76

Jit M, Choi YH, Edmunds WJ (2008) Economic evaluation of human papillomavirus vaccination in the United Kingdom. BMJ 337:a769

Karnon J, Peters J, Platt J, Chilcott J, McGoogan E, Brewer N (2004) Liquid-based cytology in cervical screening: an updated rapid and systematic review and economic analysis. Health Technol Assess 8:iii1-iii78

Krebsregister, Saarland (2003) Annual report of the epidemiological cancer register Saarland for the diagnostic years 1998 to 2000. http://www.krebsregister.saarland.de/. 1 Jul 2003

Kulasingam SL, Benard S, Barnabas R, Largeron N, Myers ER (2008) Adding a quadrivalent human papillomavirus vaccine to the UK cervical cancer screening programme: a cost-effectiveness analysis. Cost Eff Resour Alloc 6:4

Lacey C (2008) Continued efficacy of quadrivalent HPV (types 6/11/ 16/18) L1 VLP vaccine in preventing cervical or external genital disease: 4 years of follow-up. 20th European College of Obstetrics and Gynaecology, Lisbon, 4-8 March 2008

Mitchell MF, Schottenfeld D, Tortolero-Luna G, Cantor SB, Richards-Kortum R (1998) Colposcopy for the diagnosis of squamous intraepithelial lesions: a meta-analysis. Obstet Gynecol 91:626-631

Mittendorf T, Petry KU, Iftner T, Greiner W, von der Schulenburg JM (2003) Economic evaluation of human papillomavirus screening in Germany. Eur J Health Econ 4:209-215

Muñoz N, Castellsagué X, de González AB, Gissmann L (2006) Chapter 1: HPV in the etiology of human cancer. Vaccine 24 (Suppl 3):S3/1-S3/10

Myers ER, Green S, Lipkus I (2004) Patient preferences for health states related to HPV infection: visual analogue scales vs time trade-off elicitation. Proceedings of the 21st International Papillomavirus Conference, Mexico City, 20-26 February 2004

Myers ER, McCrory DC, Nanda K, Bastian L, Matchar DB (2000) Mathematical model for the natural history of human papillomavirus infection and cervical carcinogenesis. Am J Epidemiol 151:1158-1171

Olsson SE, Villa LL, Costa RL, Petta CA, Andrade RP, Malm C et al (2007) Induction of immune memory following administration of a prophylactic quadrivalent human papillomavirus (HPV) types 6/11/16/18 L1 virus-like particle (VLP) vaccine. Vaccine 25: 4931-4939

Paavonen J, Jenkins D, Bosch F, Naud P, Salmeron J, Wheeler C, Chow S, Apter D, Kitchener H, Castellsague X, de Carvalho N,
Skinner S, Harper D, Hedrick J, Jaisamrarn U, Limson G, Dionne M, Quint W, Spiessens B, Peeters P, Struyf F, Wieting S, Lehtinen M, Dubin M, HPV PATRICIA study group (2007) Efficacy of a prophylactic adjuvanted bivalent L1 virus-likeparticle vaccine against infection with human papillomavirus types 16 and 18 in young women: an interim analysis of a phase III double-blind, randomised controlled trial. Lancet 369:21612170

Petry KU, Menton S, Menton M, van Loenen-Frosch F, de Carvalho $\mathrm{GH}$, Holz B et al (2003) Inclusion of HPV testing in routine cervical cancer screening for women above 29 years in Germany: results for 8466 patients. Br J Cancer 88:1570-1577

Petry KU, Breugelmans G, Bénard S, Lamure E, Littlewood KJ, Hillemanns P (2008) Cost of screening and treatment of cervical dyskaryosis in Germany. Eur J Gynaecol Oncol 29:345-349

Robert Koch Institute (2007) Statement by the standing committee on vaccinations (STIKO) at the Robert Koch Institute: vaccination against human papilloma virus (HPV) for girls of 12 to 17 years of age - recommendation and explanatory statement. Epidemiology Bulletin 98-103

Robert Koch-Institut (2008) Gesellschaft der epidemiologischen Krebsregister in Deutschland e. V. (ed): Krebs in Deutschland 2003-2004. Häufigkeiten und Trends, 6th edn. Berlin

Schenck U, Soost HJ (1995) In Referatband der 13. Fortbildungstagung für klinische Zytologie. Befundwiedergabe in der Zytologie: Münchner Nomenklatur II und Bethesda System 1991. Märkl-Druck, Munich, pp 224-233

Schenck U, von Karsa L (2000) Cervical cancer screening in Germany. Eur J Cancer 36:2221-2226

Sheriff SK, Petry KU, Ikenberg H, Crouse G, Mazonson PD, Santas CC (2007) An economic analysis of human papillomavirus triage for the management of women with atypical and abnormal Pap smear results in Germany. Eur J Health Econ 8: $153-160$

Siebert U, Muth C, Sroczynski G, Velasco-Garrido M, Gerhardus A, Gibis B (2004) Institute for Technology Assessment. Liquidbased preparation and computer-assisted examination of cervical smears. Clinical effectiveness, economic evaluation and systematic decision analysis. Health Technology Assessment Vol 35. 1444. Series of the German Institute for Medical Documentation and Information commissioned by the Federal Ministry of Health and Social Security. Asgard, St. Augustin

Siebert U, Sroczynski G, Hillemanns P, Engel J, Stabenow R, Stegmaier C et al (2006) The German cervical cancer screening model: development and validation of a decision-analytic model for cervical cancer screening in Germany. Eur J Public Health $16: 185-192$

FUTURE II Study Group (2007) Quadrivalent vaccine against human papillomavirus to prevent high-grade cervical lesions. N Engl J Med 356:1915-1927

von Krogh G (2001) Management of anogenital warts (condylomata acuminata). Eur J Dermatol 11:598-603 